\title{
Quantification of personal thermal comfort with localized airflow system based on sensitivity analysis and classification tree model
}

Article

Accepted Version

Creative Commons: Attribution-Noncommercial-No Derivative Works 4.0

Du, C., Li, B., Liu, H., Ji, Y., Yao, R. and Yu, W. (2019)

Quantification of personal thermal comfort with localized airflow system based on sensitivity analysis and classification tree model. Energy Building, 194. pp. 1-11. ISSN 0378-7788 doi: https://doi.org/10.1016/j.enbuild.2019.04.010 Available at https://centaur.reading.ac.uk/84499/

It is advisable to refer to the publisher's version if you intend to cite from the work. See Guidance on citing.

To link to this article DOI: http://dx.doi.org/10.1016/j.enbuild.2019.04.010

Publisher: Elsevier

All outputs in CentAUR are protected by Intellectual Property Rights law, including copyright law. Copyright and IPR is retained by the creators or other copyright holders. Terms and conditions for use of this material are defined in the End User Agreement. 


\section{CentAUR}

Central Archive at the University of Reading

Reading's research outputs online 


\begin{abstract}
Although local air movement acts as a critical factor to enhance human thermal comfort and energy efficiency, the various factors influencing such movement have led to inconsistent publications on how to evaluate and design localised airflow systems in practice. This study aims to identify the main impacting factors for a localised airflow system and predict a cooling performance based on machine learning algorithms. Three typical localised airflow forms, i.e. an isothermal air supply (IASN), non-isothermal air supply (NIASN), and floor fan (FF), were deployed. The experiments were conducted under a variety of temperature/humidity/air velocity conditions in a well-controlled climate chamber, and a database including 1305 original samples was built. The primary results indicated that a classification tree C5.0 model showed a better prediction performance (83.99\%) for a localised airflow system, with 17 input parameters in the model. Through a sensitivity analysis, 8 feature variables were quantified as having significant main effect responses on subjects' thermal sensation votes (TSV), and three environmental factors (temperature, air velocity, and relative humidity) were identified as having the most significant effects. Using the 8 sensitive factors, the C5.0 model was modified with $82.30 \%$ accuracy for subject TSV prediction. A tree model demonstrating the decision rules in the C5.0 model was obtained, with air velocity $(=0 \mathrm{~m} / \mathrm{s},>0 \mathrm{~m} / \mathrm{s})$ as the first feature variable, and root node and temperature $\left(\leqslant 28{ }^{\circ} \mathrm{C},>28{ }^{\circ} \mathrm{C}\right)$ as the second feature variable and leaf node, respectively. The outcomes that provide the most influential variables and a machine learning model are beneficial for evaluating personal thermal comfort at individual levels and for guiding the application of a localised airflow system in buildings.
\end{abstract}

Keywords:

Localised airflow system; Influencing factors; Sensitivity analysis; Classification tree model; Thermal sensation prediction.

\title{
Nomenclature
}

\begin{tabular}{|l|l|l|l|}
\hline PCS & personalised comfort system & $\mathrm{TSV}_{\text {overall }}$ & overall thermal sensation \\
\hline HVAC & $\begin{array}{l}\text { heating, ventilation and air- } \\
\text { conditioning }\end{array}$ & $\mathrm{TSV}_{\text {head }}$ & thermal sensation for head \\
\hline IASN & isothermal air supply nozzle & $\mathrm{TSV}_{\text {chest }}$ & thermal sensation for chest \\
\hline NIASN & non-isothermal air supply nozzle & $\mathrm{TSV}_{\text {back }}$ & thermal sensation for back \\
\hline FF & floor fan & $\mathrm{TSV}_{\text {hand }}$ & thermal sensation for hand \\
\hline $\mathrm{T}$ & Air temperature in the chamber & $\mathrm{TSV}_{\text {lower }}$ & $\begin{array}{l}\text { thermal sensation for lower } \\
\text { body part }\end{array}$ \\
\hline $\mathrm{RH}$ & Relative humidity in the chamber & $\mathrm{T}_{\text {head }}$ & head skin temperature \\
\hline $\mathrm{V}$ & $\begin{array}{l}\text { Air velocity for the localised } \\
\text { airflow system }\end{array}$ & $\mathrm{T}_{\text {chest }}$ & chest skin temperature \\
\hline
\end{tabular}




\begin{tabular}{|l|l|l|l|}
\hline SA & sensitivity analysis & $\mathrm{T}_{\text {back }}$ & back skin temperature \\
\hline AD & body surface area & $\mathrm{T}_{\text {upper }}$ & upper arm skin temperature \\
\hline BMI & body mass index & $\mathrm{T}_{\text {lower }}$ & lower arm skin temperature \\
\hline SVM & support vector machine & $\mathrm{T}_{\text {hand }}$ & hand skin temperature \\
\hline ANN & artificial neural network & $\mathrm{T}_{\text {thigh }}$ & thigh skin temperature \\
\hline SD & Standard deviation & $\mathrm{T}_{\text {calf }}$ & calf skin temperature \\
\hline & & $\mathrm{T}_{\text {overall }}$ & Mean skin temperature \\
\hline
\end{tabular}




\section{Introduction}

The personalised comfort system (PCS), which was designed to respond to the energy crisis in the 1970s[1, 2] and to locally change an indoor environment independently from a heating, ventilation, and air-conditioning (HVAC) system, has been acknowledged to benefit both thermal comfort and energy efficiency[3, 4]. The local means of a PCS are targeted to affect the most sensitive body parts to achieve overall comfort, and thus push the boundaries of conventional comfort zones. An extended comfort zone can be achieved from $16^{\circ} \mathrm{C}$ to $20^{\circ} \mathrm{C}$ with personalised warming, and from $27^{\circ} \mathrm{C}$ to $30^{\circ} \mathrm{C}$ or more with air velocity adjustments[5]. Most importantly, it consumes a relatively smaller amount of energy. A field study found that through applying personal devices and adjusting HVAC supply air set-points, the occupants' satisfaction increased from $56 \%$ to over $80 \%$, while lowering HVAC energy consumption by $60 \%$ in heating and $40 \%$ in cooling [6]. It is generally estimated that using a PCS can potentially achieve approximately 15\%-30\% energy savings, with great user satisfaction $[7,8]$.

A localised airflow system, as a crucial type of PCS, has attracted considerable focus from researchers in both field surveys and lab experiments. Employing a fan to increase airflow indoors is the most frequent behaviour by occupants in buildings to extend their comfort zones in the summer $[9,10]$. One on-site observation by Mustapa et al. [11] showed that the use percentage of floor fans was $5.1 \%$ in air-conditioned buildings, but up to $19.4 \%$ in naturally-ventilated buildings. A higher fan use proportion of $64 \%$ was obtained in a long-term case study, and increased in summer with the upper limit of the comfort temperature, up to $28^{\circ} \mathrm{C}$ [12]. In-depth research regarding the relationships between air movement and thermal comfort with localised airflow systems has been performed via lab experiments. A variety of operating parameters, such as environmental contexts[13, 14], airflow velocity and turbulence [15-17], the temperature of supplied air [18], the types of different air supply structures [19-21], and locally-exposed body parts [22] were examined as having effects on user comfort, to varying degrees. Additionally, studies [23, 24] that focused on occupant behaviours regarding the local air supply systems further addressed the significant influence of personal controls: the upper acceptable temperature limit was increased when the air supply was accessibly regulated at individual levels. Later, Zhang et al. [7] summarised five typical PCS models reviewed in current studies, and defined a term "corrective powder" to quantify the cooling efficiency of the different PCS models. It was concluded that the offset temperatures ranged from $1{ }^{\circ} \mathrm{C}$ to $6{ }^{\circ} \mathrm{C}$ for cooling, and from $2{ }^{\circ} \mathrm{C}$ to $10^{\circ} \mathrm{C}$ for heating. However, these findings are hardly comparable to one another, as variant factors and conditions exist in different experimental designs, all of which remarkably affect the performance of localised airflow systems. As such, no consistent results are available for how to evaluate and design a localised airflow system in building environments[7], which thwarts its real practical application and wider energy saving potential. 
A machine learning methodology for problem solving has received increased attention in many research fields, thanks to its abilities to improve model prediction performance through continuous learning, and to handle complex and high-dimensional data [25]. Driven by the building technology improvement and wireless sensor-rich environments, researchers have shifted their paradigms to a variety of machine learning algorithms to obtain relationships between human thermal comfort and a number of factors, aiming to achieve better predictions/evaluations on human thermal comfort and applications in buildings. Kim et al. [26] integrated field data of environmental conditions and mechanical system settings as well as occupants' control behaviours on a PCS, and predicted the individuals' thermal comfort responses using six machine learning algorithms. The results indicated that employing a machine learning technique enabled a median prediction accuracy of 0.73 , as compared to conventional models (predicted mean vote (PMV), adaptive model) that produced a median accuracy of 0.51 . Similarly, Jiang [27] adopted a C-Support Vector Classification (C-SVC) algorithm to predict a personal thermal sensation in a PCS; the results showed a higher predictive accuracy $(89.82 \%)$ as compared to the PMV model (49.71\%), which was beneficial for optimisation control for the PCS. Further, Kim [28] emphasised the new paradigm of using machine learning methods for personal comfort models; such models enable predictions at individual levels instead of the average responses of a large population, and significantly improve the prediction accuracy by approximately 17\%-40\%, reinforcing the potential of a PCS in real-world applications. Based on real-time feedback and automatic regulation, employing extreme learning machines and neural networks results in a predicted maximum energy saving rate of $30 \%$ for air-conditioning and mechanical ventilation systems, while maintaining a pre-defined comfort [29]. However, though these works provide valuable insights for using machine learning techniques to improve the prediction performance with a PCS, there is still a paucity of research for gaining a holistic understanding of the various driving factors for a localised airflow system, and identifying an appropriate machine learning model to evaluate personal thermal comfort. Moreover, there has been insufficient examination of how to determine which factors should be considered for localised airflow systems, to what degree the model inputs affect the target variable, and how to guide the evaluation and designs of such localised airflow systems in real-life buildings.

With new devices and technologies of localised airflow systems being increasingly accessible for indoor building environments, identifying the most significant factors and an appropriate evaluation model covering all these factors is of great importance, before such systems are applied in buildings to achieve building energy savings. As a result, this study is based on a collective database of several lab experiments for localised airflow systems and conducts a rigorous process to explore the influencing factors and evaluate models for local airflow conditions. The aims of this study are to quantify the relative significance of factors by referring to sensitivity analysis and identify a prediction model of personal comfort based on the advantages of machine learning algorithms. This work is expected to provide an in-depth understanding of 
factor interactions in a localised airflow system and enable a more informed appraisal of localised airflow system design in practice. The outcomes can aid in guiding data monitoring and collection efforts when a localised airflow system is applied in buildings in the future to improve personal thermal comfort prediction and energy efficiency in buildings.

\section{Methods}

We conducted multiple laboratory experiments to examine the relationships between local air supply and human thermal comfort in warm and hot environments and built a database. For personalised ventilation, it has been found that airflow is preferred by people when it is directed against the upper parts of the body (e.g. face, head, chest)[30,31] and that a transverse flow improves thermal comfort. Therefore, we selected three typical localised airflow systems, i.e. isothermal air supply nozzle (IASN), non-isothermal air supply nozzle (NIASN), and floor fan (FF). The difference between the IASN and NIASN systems is the temperature difference of the supplied air. The FF was considered as a common local airflow device in buildings to increase air movement, wherein the air supply type differed from the IASN system. All experiments were performed during the summer season in different periods from 2014 to 2017 and covered the main factors we aimed to explore for a localised airflow system. An introduction is briefly presented as follows, to support an improved understanding of the experiments and the database used.

\subsection{Climate chamber}

All three series of experiments were performed in a climate chamber with a size of $4 \mathrm{~m} \times 3 \mathrm{~m} \times 3 \mathrm{~m}(\mathrm{~L} \times \mathrm{W} \times \mathrm{H})$. The air temperature $(\mathrm{T})$ and relative humidity $(\mathrm{RH})$ in the chamber were managed by an automatic control system with a temperature range of $10^{\circ} \mathrm{C}-40{ }^{\circ} \mathrm{C}$ (accuracy: $\pm 0.3{ }^{\circ} \mathrm{C}$ ) and $\mathrm{RH}$ range of $10 \%-90 \%$ (accuracy: $\pm 5 \%$ ). The handled air was sent to the chamber using a perforated ceiling, such that the ambient air velocity in the chambers not generated by the local airflow system did not exceed $0.1 \mathrm{~m} / \mathrm{s}$ during experiments. This ensured a uniform surrounding environment and a lack of disturbances of the airflow during experiments. A special insulation construction of the chamber ensured conditions such that the mean radiant temperature was equal to the room air temperature. In addition, the climate chamber was connected to an airconditioned room that was controlled at a neutral thermal environment $\left(26^{\circ} \mathrm{C} / 50 \% \mathrm{RH}\right)$ for preparation work before each test.

\subsection{Subjects}

The subjects in experiments were recruited from college students. Before the experiments, a priori power analysis in $\mathrm{G}^{*}$ Power 3 [32] was conducted to determine the sample capacity, according to the designs in each series of experiments. All participants were volunteers between 20 and 25 years of age, with healthy conditions, e.g. no colds or fever. They were paid to participate in all of the design conditions in each series of experiments. Before enrolment in the tests, each subject received verbal and written explanations of the study. Written informed consent was obtained from the 
subjects. The basic information of participants was collected at the first time they attended the test, as summarised in Table 1. In addition, uniform summer clothes (cotton short-sleeved T-shirt, thin trousers, and slippers, with clothing insulation of $0.4 \mathrm{clo[33]}$ ) were provided to subjects in the experiments, to minimise the effect of clothing insulation on subjective thermal perceptions.

Table 1 Basic anthropometric data of subjects(mean \pm SD)

\begin{tabular}{cccccc}
\hline Conditions & Number & Sex & Age $($ years $)$ & Height $(\mathrm{cm})$ & Weight $(\mathrm{kg})$ \\
\hline $\begin{array}{c}\text { Isothermal } \\
\text { air supply }\end{array}$ & 18 & male & $24.5 \pm 1.2$ & $174.2 \pm 5.2$ & $62.6 \pm 5.5$ \\
$\begin{array}{c}\text { nozzle } \\
\text { (IASN) }\end{array}$ & & & & & \\
\hline $\begin{array}{c}\text { Non- } \\
\text { isothermal }\end{array}$ & 8 & male & $23.6 \pm 1.4$ & $175.1 \pm 6.1$ & $70.0 \pm 10.5$ \\
$\begin{array}{c}\text { air supply } \\
\text { nozzle }\end{array}$ & 8 & female & $23.4 \pm 1.2$ & $161.5 \pm 6.4$ & $51.3 \pm 4.8$ \\
(NIASN) & & & & & \\
\hline $\begin{array}{c}\text { Floor Fan } \\
\text { (FF) }\end{array}$ & 8 & male & $23.7 \pm 0.9$ & $174.2 \pm 6.1$ & $63.3 \pm 5.9$ \\
\hline
\end{tabular}

\section{1}

132

133

134

135

136

137

138

139

140

141

142

\subsection{Experimental designs}

Among all three types of localised airflow systems, local air was directly supplied in front of the subjects. As shown in Figure 1, the IASN and NIASN systems were made of a ventilation duct with plastic batches $(\mathrm{d}=150 \mathrm{~mm})$ and equipped with a nozzle $(\mathrm{d}=100 \mathrm{~mm})[34]$. Variable nozzle types and sizes were exclusively considered in this study. The supply-air outlet was placed $30-40 \mathrm{~cm}$ from the subjects, with an adjustable angle to aim at a subject's face and head horizontally, or to aim in a slightly downward slope, e.g. to aim at the neck and chest. The FF was located $1.5 \mathrm{~m}$ horizontally in front of the subjects and was placed approximately $0.9 \mathrm{~m}$ above the floor level, and it directed a forced airflow to the head and chest region. A general view of the local airflow system used in the experiments is shown in Figure 1.
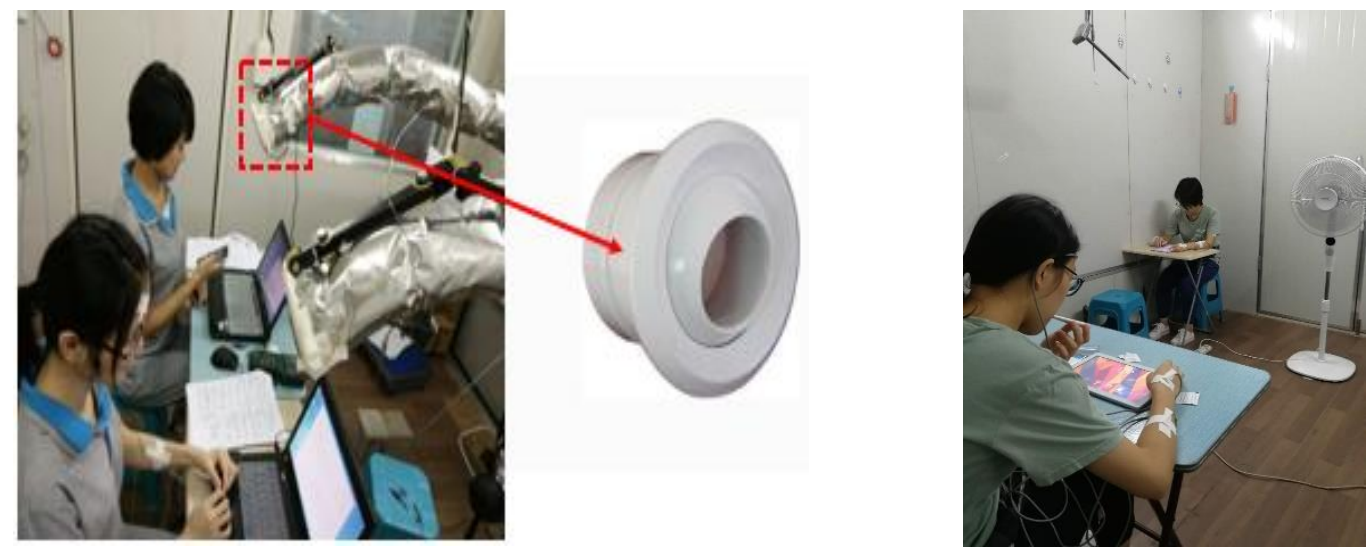


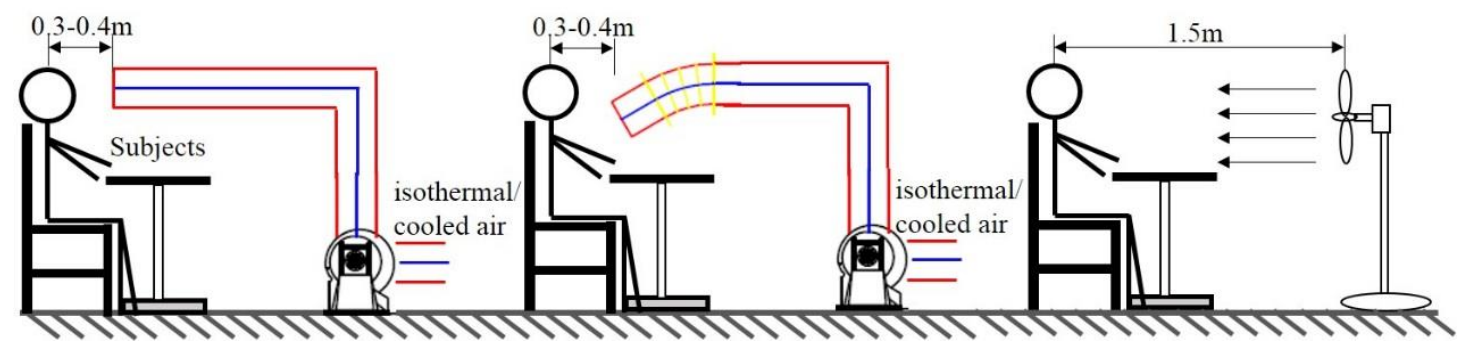

143

144

145

146

147

148

149

150

151

152

153

154

155

156

157

158

159

160

161

162

163

164

165

Figure 1 Schematic of the three localised airflow systems

Considering that local airflows given to upper body parts were more sensitive and efficient for cooling $[35,36]$, we mainly focused on three factors for airflow, i.e. the $\mathrm{V}$ at locations where subjects were exposed, temperature of the supplied air, and body parts exposed to the airflow. In addition, as air velocity has been acknowledged to offset temperature increases in warm settings, all of the experiments were designed in warm/hot environments, with T ranging from $26^{\circ} \mathrm{C}$ to $32^{\circ} \mathrm{C}$, and RH from $50 \%$ to $90 \%$. The design conditions in the three series of experiments are summarised in Table 2.

For the NIASN system, the temperature of the supplied air shown in Table 2 was controlled by a constant temperature-humidity air-conditioned system in an adjacent room, and the cooled air at the designed levels was supplied to the chamber through plastic ducts; for the IASN system, the supplied air was circulated by fans from ambient air in the chamber. The designed V in Table 2 for the NIASN system was slightly lower than that for the IASN system, in accordance with the cooling effect of the low temperature of the air supplied in IASN system. The different body parts exposed to airflow were achieved by regulating the angles of the supply air outlet (see Figure 1) in these two systems. It should be noted that the $\mathrm{V}$ given in Table 1 for all three localised airflow systems are designed values referring to places where subjects were located, rather than at the outlets (see the lower part of Figure 1). This was to determine a comfortable $\mathrm{V}$ for subjects. The $\mathrm{V}$ under each condition was regulated and measured during preparation work, with no subjects. The regulations were recorded, and before each test, the $\mathrm{V}$ would be preset at the designed level.

\begin{tabular}{|c|c|c|c|c|c|}
\hline Conditions & $\mathrm{T}^{*}\left({ }^{\circ} \mathrm{C}\right)$ & $\mathrm{RH}(\%)^{*}$ & $\mathrm{~V}(\mathrm{~m} / \mathrm{s})^{*}$ & $\begin{array}{c}\text { Supply Air } \\
\text { Temperature }\left({ }^{\circ} \mathrm{C}\right) * *\end{array}$ & $\begin{array}{l}\text { Local Body } \\
\text { Parts }\end{array}$ \\
\hline \multirow{9}{*}{ IASN } & 28 & \multirow{9}{*}{55} & \multirow{2}{*}{$0 / 1.4$} & 28 & head \\
\hline & 20 & & & 28 & chest \\
\hline & \multirow{2}{*}{30} & & \multirow{2}{*}{$0 / 1.8$} & 30 & head \\
\hline & & & & 30 & chest \\
\hline & \multirow{2}{*}{32} & & \multirow{2}{*}{$0 / 2.2$} & 32 & head \\
\hline & & & & 32 & chest \\
\hline & 28 & & \multirow{3}{*}{ 0/1/1.4/1.8 } & 28 & head+chest \\
\hline & 30 & & & 30 & head+chest \\
\hline & 32 & & & 32 & head+chest \\
\hline NIASN & 26 & 75 & 0/0.6/0.8/1.0/1.2 & 25 & head \\
\hline
\end{tabular}




$\begin{array}{cccc}28.0 \pm 0.2 & 50.5 \pm 1.0 & 0 / 1.13 \pm 0.07 / 1.32 \pm 0.05 / 1.90 \pm 0.09 & 28.0 \pm 0.2 \\ 27.9 \pm 0.2 & 69.6 \pm 0.8 & 0 / 1.1 \pm 0.1 / 1.29 \pm 0.08 / 1.91 \pm 0.08 & 27.9 \pm 0.2 \\ 28.1 \pm 0.2 & 89.5 \pm 1.2 & 0 / 1.08 \pm 0.1 / 1.90 \pm 0.08 / 2.42 \pm 0.05 & 28.1 \pm 0.2 \\ 30.2 \pm 0.1 & 49.8 \pm 1.0 & 0 / 1.11 \pm 0.1 / 1.88 \pm 0.07 / 2.4 \pm 0.10 & 30.2 \pm 0.1 \\ 29.9 \pm 0.2 & 70.4 \pm 0.9 & 0 / 1.12 \pm 0.07 / 1.93 \pm 0.05 / 2.39 \pm 0.1 & 29.9 \pm 0.2 \\ 30.1 \pm 0.2 & 89.5 \pm 1.1 & 0 / 1.31 \pm 0.06 / 1.91 \pm 0.04 / 2.43 \pm 0.05 & 30.1 \pm 0.2 \\ 27.9 \pm 0.2 & 51.2 \pm 0.8 & 0 / 1.29 \pm 0.13 / 1.85 \pm 0.11 / 2.41 \pm 0.08 & 27.9 \pm 0.2 \\ 27.9 \pm 0.1 & 70.5 \pm 1.2 & 0 / 1.92 \pm 0.08 / 2.38 \pm 0.11 / 2.82 \pm 0.1 & 27.9 \pm 0.1 \\ 28.1 \pm 0.2 & 91.2 \pm 0.9 & 0 / 1.88 \pm 0.1 / 2.4 \pm 0.13 / 2.82 \pm 0.1 & 28.1 \pm 0.2\end{array}$

$180 \quad$ Note:

$181 *$ the temperature of the supplied air in IASN and NIASN systems was measured at outlets using

182 thermocouples (range: $-20{ }^{\circ} \mathrm{C}-+85{ }^{\circ} \mathrm{C}$, accuracy: $\pm 0.1{ }^{\circ} \mathrm{C}$, PyroButton-T, Opulus, US); the

183 temperature of the supplied air in FF system was defaulted to ambient air temperature.

184

\subsection{Variables and measurements}

Many factors influence the cooling effect of local airflow on human thermal comfort. With the aim of identifying significant variables, we classified possible factors into four categories, namely environmental, individual, physiological, and psychological, and selected representative parameters in each category for further analysis.

A thermal comfort monitoring station instrument was used to measure the realtime $\mathrm{T}$ and $\mathrm{RH}$ in the chamber (MI6401, Germany, Accuracy: $\mathrm{T} \pm 0.2{ }^{\circ} \mathrm{C}, \mathrm{RH} \pm 2 \%$ ), to ensure that the experimental environments met the designed demands. The instrument was placed in the central chamber, at a height of $0.6 \mathrm{~m}$ above the floor and $0.5 \mathrm{~m}$ away from subjects. Before each test, when no subject was present, the $\mathrm{V}$ at the subject exposing location was pre-regulated and measured to reach the designed level in Table 2, using an Air Distribution Measuring System (AirDistSys 5000, Sensor Electronic, Poland, range: $0.05 \mathrm{~m} / \mathrm{s}-5 \mathrm{~m} / \mathrm{s}$, accuracy: $\pm 0.02 \mathrm{~m} / \mathrm{s} \pm 1 \%$ reading data). To evaluate an environmental air velocity for thermal comfort, a weighted average of the indoor air velocity was calculated. The weighted average was calculated based on measurements performed at levels representing heights of ankles, abdomen, and neck (0.1, 0.6 and 1.1 $\mathrm{m}$ for seated occupants, respectively) during tests, and according to the American Society of Heating, Refrigerating and Air-Conditioning Engineers (ASHRAE) Standard 55 [33] and European standards [37, 38]. A portable hot wire anemometer (VT110, France, $0.15 \mathrm{~m} / \mathrm{s}-30 \mathrm{~m} / \mathrm{s}, \pm 3 \%$ reading data with $\pm 0.05 \mathrm{~m} / \mathrm{s}$ ) was used every 5 min repeatedly, to verify whether the actual $\mathrm{V}$ met the designed level in Table 2. The values at the three levels were then averaged to represent the mean air velocity in the room when necessary.

The parameters that were considered influential for individuals were sex, body surface area (AD), and body fat ratio, which were believed to affect body heat generation and heat loss and thus affect the sensation of airflow. As shown in Table 1,

212 the first time subjects attended the tests, each subject's weight and height were 
measured. The AD values for each subject were calculated by Equation (1)[39]. The body fat ratio was indirectly calculated using body mass index(BMI), referring to Equation (2).

$$
\begin{aligned}
& \mathrm{A}_{\mathrm{D}}=0.202 \mathrm{~W}_{\mathrm{b}}{ }^{0.425} \mathrm{H}_{\mathrm{b}}{ }^{0.725} \\
& \mathrm{BMI}=\mathrm{W}_{\mathrm{b}} / \mathrm{H}_{\mathrm{b}}^{2}
\end{aligned}
$$

Where $\mathrm{H}_{\mathrm{b}}$ is the body height, $\mathrm{m}$; $\mathrm{W}_{\mathrm{b}}$ is the body weight, $\mathrm{kg}$.

In warm/hot environments, body heat dissipation commonly occurs through two major mechanisms, namely cutaneous vasodilation and sweating, which affect skin temperatures and convective and evaporative heat transfer from the core to the skin[40]. During experiments, the local skin temperatures from eight parts of the body (i.e. forehead, left chest, left back, left upper arm, left lower arm, left hand, right anterior thigh, and anterior calf), were measured by thermocouples (TSD202B, BIOPAC, US, temperature range: $0-70{ }^{\circ} \mathrm{C}$, accuracy: $\pm 0.1^{\circ} \mathrm{C}$ ), while using surgical, water permeable, adhesive tapes. The data were recorded at $0.5 / \mathrm{s}$ and logged by a multi-channel physiological acquisition system (MP150-SKT100C, BIOPAC, US). The mean skin temperature $\left(\mathrm{T}_{\text {overall }}\right)$ was calculated using an area-weighted eight-point method (Equation (3) ) [41].

$$
\mathrm{T}_{\text {overall }}=0.07 \mathrm{~T}_{\text {head }}+0.175 \mathrm{~T}_{\text {chest }}+0.175 \mathrm{~T}_{\text {back }}+0.07 \mathrm{~T}_{\text {upper }}+0.07 \mathrm{~T}_{\text {lower }}+0.05 \mathrm{~T}_{\text {hand }}+0.2 \mathrm{~T}_{\text {thigh }}+0.19 \mathrm{~T}_{\text {calf }}
$$

where the $\mathrm{T}_{\text {overall }}$ is the mean skin temperatures, ${ }^{\circ} \mathrm{C}$; $\mathrm{T}_{\mathrm{i}}$ is the local skin temperature of the head, chest, back, upper arm, lower arm, hand, thigh, and calf, ${ }^{\circ} \mathrm{C}$.

Studies had previously suggested that a whole body thermal sensation was a result of the integrated effect of whole and local thermal responses, where the local body parts took significant proportions in affecting the whole body thermal sensation under local airflow environments [35, 36, 42, 43]. Therefore, we considered the interactions of subjects' whole and local thermal perceptions and designed questionnaires for both whole and local thermal evaluation. The most common thermal sensation vote (TSV) scale was used: -3 cold, -2 cool, -1 slightly cool, 0 neutral, +1 slightly warm, +2 warm, and +3 hot, as described in the ASHRAE 7-point scale[33]. Subjects were asked to evaluate a thermal sensation on the whole body, head, chest, back, hand, and lower body, under local airflow conditions. In some situations, when the subjects had difficulties in expressing judgements, he/she was allowed to use middle votes between the above values (e.g. +1.5 between +1 and +2 ). Additional questions were also involved in the questionnaire to evaluate subjects' sensation to humidity, air velocity, environmental expectations, environmental acceptability, and so on. Considering this study concerns the offset of a local airflow on acceptable temperature limits, the main dependent variable being focused on is the thermal sensation. Therefore, these indices were exclusively analysed in the following parts.

\subsection{Experimental protocols}

The experiments complied with the guidelines in the Declaration of Helsinki[44]. Participants were counselled to withdraw from the experiments at any point in time if they were not comfortable during the tests. 
For each test, subjects were asked to arrive at the adjacent room $30 \mathrm{~min}$ in advance, to change into uniform clothes, attach thermocouples, and stabilise their metabolic rates. During this period, the details of experimental process and questionnaires were explained to them.

The formal experiment began after the subjects entered the chamber and were seated at desks. For each test, they experienced different conditions, with and without a local air supply. Blind to the experimental settings, the subjects were exposed to two or three levels of $\mathrm{V}$ for $20 \mathrm{~min}$, and intermittent recovery for 15-20 min (without air supply) during each test. The different air velocities in each condition were regulated by experimenters according to the preset measurements, and were supplied in a random way during the whole experimental process. The $\mathrm{T}$ and $\mathrm{RH}$ in the chamber were kept constant, at the designed levels. Over the period of testing, the local skin temperatures of each subject were measured continuously; meanwhile, they were asked to fill in identical questionnaires every $5 \mathrm{~min}$ to report their thermal perceptions. During the whole experiment, the subjects performed standardised office work while avoiding walking, talking, and other intensive activities.

\subsubsection{Data collection}

The experiments adopted 17 variables to comprehensively identify the significant influencing factors. They included 3 individual factors (i.e. sex, AD, BMI), 5 environmental factors (i.e. T, RH, V, supplied air temperature, and local exposed body parts), 9 physiological factors (i.e. $\mathrm{T}_{\text {head }}, \mathrm{T}_{\text {chest }}, \mathrm{T}_{\text {back }}, \mathrm{T}_{\text {upper }}, \mathrm{T}_{\text {lower }}, \mathrm{T}_{\text {hand }}, \mathrm{T}_{\text {thigh }}, \mathrm{T}_{\text {calf }}$, and $\left.\mathrm{T}_{\text {overall }}\right)$. In addition, 6 subjective indices ( $\mathrm{TSV}_{\text {overall }}, \mathrm{TSV}_{\text {head, }}, \mathrm{TSV}_{\text {chest }}, \mathrm{TSV}_{\text {back}}, \mathrm{TSV}_{\text {hand }}$, and $\mathrm{TSV}_{\text {lower body }}$ ) were also investigated using questionnaires. The original experimental data were collected and saved in SPSS 22.0 software. As the study mainly focused on subjects' stable thermal responses to local airflow, a repeated measure of analysis of variance (ANOVA) was firstly performed for subjects' skin temperatures, to determine the stable time of subjects' thermal responses during tests under each condition. The stable time was determined as that having no significant difference between subject' skin temperatures at one-time point and thereafter. The results showed that majority of subjects' skin temperatures stabilised quickly, during the initial $10 \mathrm{~min}$ when they were exposed to airflow. Then, all of the data for each subject were averaged (mean $\pm \mathrm{SD}$ ) for the last $10 \mathrm{~min}$ at each stage during the tests, either with airflow or without airflow. The new database included 1305 sample cases, which were built and used for the following analysis. To explore the correlation and interaction between variables, a Pearson correlation coefficient analysis was employed for continuous variables, and Spearman correlation coefficients were employed for categorical variables. A p-value below 0.05 indicated statistical significance during the analysis.

\subsubsection{Machine learning models}

Research has provided robust evidence for the application of a variety of machine learning algorithms, to better predict human thermal comfort[28] at individual levels. 
Bayesian network [48], Gaussian process [49], support vector machine (SVM) [27, 50], and artificial neural network(ANN) [51]. These models enable using a variety of factors to solve the complexity of variant variables in models, and concentrate exclusively on the target output. This is an advantage in PCS studies, which have a large number of confounding factors.

One objective of this study is to deploy the advantages of the machine learning methods to explore an appropriate model to predict the personal comfort for a localised airflow system. The SPSS Modeler 20.0, as a data mining tool, offers multiple machine learning techniques and supports a variety of classification and regression models[52]. Given many algorithms exist in machine learning[25], this study first employed the SPSS Modeler 20.0 to select the well-matched generative and deterministic machine learning models according to the experimental database. One benefit of the SPSS Modeler is that it can provide an intuitive graphical interface to help visualise each step in the data mining process as part of a stream. Figure 2 shows the primary analysis processing in SPSS Modeler, including experimental data processing and model screening. After those steps, 11 models are further examined in the following parts: logistic regression, discriminative model, Bayesian network, ANN, Lagrangian SVM 314 (LSVM), C5.0, Tree-AS, chi-squared automatic interaction detection (CHAID), classification and regression tree (C\&RT), Quest, and Random Tree.

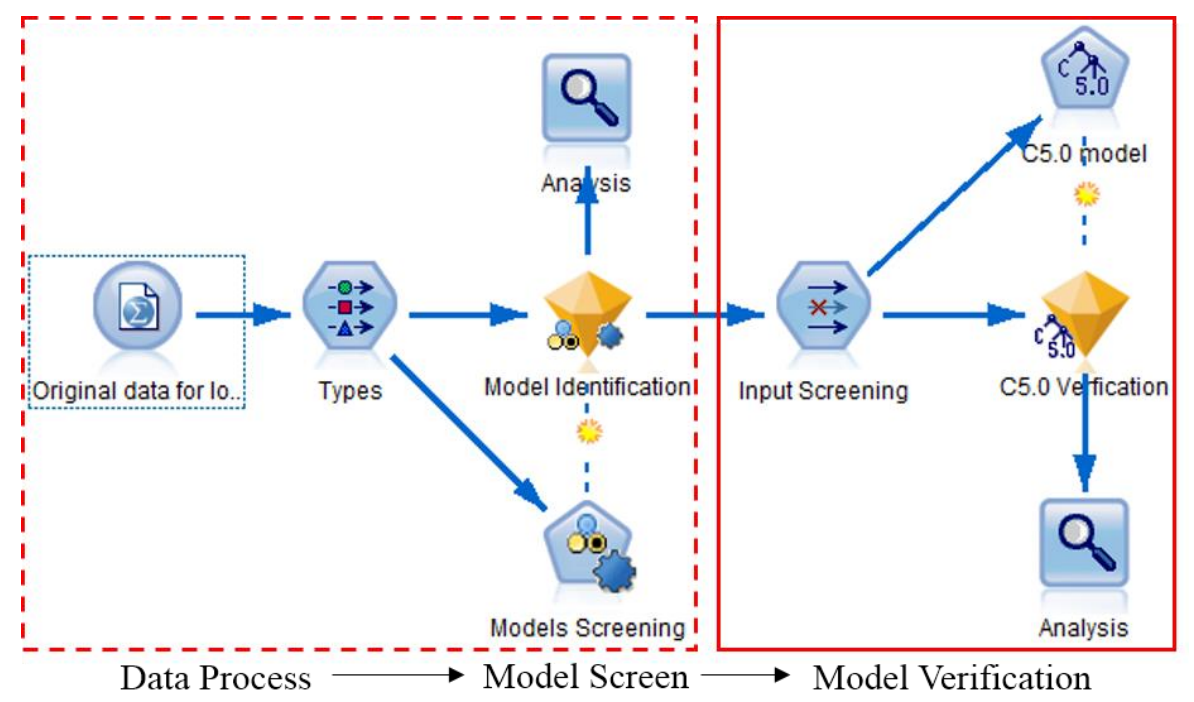

Figure 2 Analysis process in SPSS Modeler using experimental data

\subsubsection{Sensitivity analysis (SA)}

As nearly 20 impacting factors were considered in this study for a localised airflow system, it is impractical to cover all of these data in models for a building application. Therefore, it is necessary to first identify significant variables, e.g. those with better explanations of human thermal comfort under local airflow conditions. A sensitivity analysis (SA) is a targeted method that enables determination of how the variation of the output in a model can be apportioned among the inputs[53]. The SA has been widely applied in academic research, and has been used in practical application in a variety of fields [54]. The method has also been considered as a powerful tool for building 
optimisation in building design, and for exploring influencing variables on a specific target in a building energy simulation[55, 56]. However, as there are several methods to perform the SA, less attention has been paid to explore the application in multiclass classification, and in particular with the various categorical and numerical features in a thermal comfort evaluation for a PCS. In this study, we referred to a variance-based SA methodology based on a Bayesian treed Gaussian process model in the "tgp" package, [57] and conducted the analysis via R software (ver. 3.3.2). The outcomes enable us to understand and quantify the main effects of variables on a dependent variable, as well as the first order and total sensitivity indices among the input variables. The significance level was set at $95 \%(\mathrm{p}<0.05)$.

\section{Results analysis}

Based on the dataset of 1305 original samples from the three series of experiments, the following section aims to explore which models are superior for thermal comfort evaluation in a localised airflow system at individual levels, as well as the representative factors that have the most significant effects on personal thermal comfort. 3.1 Machine learning models identification for localised airflow system

Although both local and whole thermal sensations of subjects were measured during the experiments, an interactive effect exists among these indices. Therefore, we employed the typical whole body (overall) thermal sensation $\mathrm{TSV}_{\text {overall }}$ as the target dependent variable to examine its relation to the variant independent variables and build models.

After determining the 17 input variables (see Section 2.4) and the target output, the dataset was randomly split into training and testing sets (80\% and 20\%), and all of the 11 machine learning models mentioned in Section 2.6.2 were tested using the SPSS Modeler 20.0. Figure 2 depicts the conducting process in the SPSS Modeler. In that regard, this study does not discuss the detailed process of data training and parameter tuning in these algorithms. Instead, we focused on comparing the prediction performance among these models to identify the appropriate model. Table 4 summarises the preferred five models from the set of 11 models and lists their prediction performances. From Table 4, it can be seen that the C5.0 model displays the highest prediction performance of $83.99 \%$ when all 17 variables are included, followed by $59.69 \%$ for the CHAID model, and $57.47 \%$ for the C\&RT model. The Quest and ANN models were worse than the first three classification tree models, with their predictive performances at $53.56 \%$ and $44.9 \%$, respectively. As the C5.0 model takes the information gain as a standard to optimise the partition process and favours outcomes with a higher information gain, the results indicate that the C5.0 model is superior for predicting subjects' thermal sensations under local airflow conditions. Therefore, we give priority to the C5.0 model in the following analysis to profile the relationship between subjects' thermal sensations and variant input features in localised airflow systems. 
Table 4 Preferred machine learning models

\begin{tabular}{lll}
\hline Models & Prediction Performance & Number of Input Variables \\
\hline C5.0 & $83.99 \%$ & 17 \\
CHAID & $59.69 \%$ & 9 \\
C\&RT & $57.47 \%$ & 14 \\
Quest & $53.56 \%$ & 10 \\
ANN & $44.91 \%$ & 17 \\
\hline
\end{tabular}

370

\subsection{SA for impacting factors in localised airflow system}

\subsubsection{Feature variable screening}

From Table 4, it is not surprising that the C5.0 model possesses a better prediction performance, as too many variables are involved in the model. Practically speaking, owing to the difficulties and expenses of monitoring all influential variables, choosing a good model is not only based on accuracy, but also on the validity and explanatory ability of the selected data [26]. Therefore, it may be difficult to capture all the relevant information for the C5.0 model to develop a comfort prediction; otherwise, it is necessary to correlate the comfort prediction with highly representative variables. In fact, some variables in the dataset interact with each other to influence subjects' thermal sensations, and some are negligible for model prediction. Therefore, we first conducted a correlation analysis to examine the 17 variables in the C5.0 model, to possibly reduce the number of input variables.

First of all, because of the limited distance $(30-40 \mathrm{~cm})$ between the supplied air outlet and the subjects in the IASN system, both the head and chest of subjects were exposed to air movement in the experiments, which made the boundaries fuzzy in distinguishing the body areas exposed to airflow. In that case, the factors of different exposed parts for the body are exclusively considered. Moreover, some previous studies $[58,59]$ confirmed that the temperature difference between the supplied air from a nozzle and the surroundings was negligible when the air reached the subjects, resulting from the diffusing effect of the supplied air. The measurements of the air flow field during pre-experiments had also found that the temperature of the cooled air attenuated quickly in a NIASN system, being equal to the ambient temperatures in warm and hot conditions. Thus, the temperature variable of supplied air is also removed when evaluating the cooling effect of local air movement. After that, the environmental parameters were reduced to three: $\mathrm{T}, \mathrm{RH}$, and V.

As for physiological variables, Dai et al. [50]discussed that the curse of dimensionality may occur with additional local body skin temperatures as inputs for thermal demand predictions, based on a SVM classifier. Therefore, a Pearson correlation analysis was performed first, and the correlation metrics of these physiological indices are illustrated in Table 5. From Table 5, it can be seen that there were no significant correlations between the skin temperatures of the chest and other 
parts. During experiments, the thermocouples were placed at the upper left part of the chest, and were directly exposed to the air and V. Therefore, it was reasonable that the subjects' chest skin temperatures were more sensitive to local airflow than other body parts (see Figure 1). In addition, the correlation coefficients in Table 5 (marked in grey colour) show that the $\mathrm{T}_{\text {overall }}$ was significantly related to local skin temperatures. As a result, the mean skin temperature $\mathrm{T}_{\text {overall }}$ can be a feature selected to represent the local skin temperatures. After analysis, the physiological variables can be reduced to two: $\mathrm{T}_{\text {overall }}$ and $\mathrm{T}_{\text {chest. }}$

Table 5 Correlation analysis of subjects' physiological indices

\begin{tabular}{llllllllll}
\hline Variances & $\mathrm{T}_{\text {head }}$ & $\mathrm{T}_{\text {chest }}$ & $\mathrm{T}_{\text {back }}$ & $\mathrm{T}_{\text {upperarm }}$ & $\mathrm{T}_{\text {lowerarm }}$ & $\mathrm{T}_{\text {hand }}$ & $\mathrm{T}_{\text {thigh }}$ & $\mathrm{T}_{\text {calf }}$ & $\mathrm{T}_{\text {overall }}$ \\
\hline $\mathrm{T}_{\text {head }}$ & 1.00 & 0.008 & $0.253^{* *}$ & $0.097^{* *}$ & 0.017 & $0.023^{* *}$ & $0.445^{* *}$ & $0.173^{* *}$ & $0.283^{* *}$ \\
$\mathrm{~T}_{\text {chest }}$ & & 1.00 & 0.012 & 0.013 & -0.001 & 0.000 & 0.033 & 0.001 & 0.023 \\
$\mathrm{~T}_{\text {back }}$ & & & 1.00 & $0.086^{* *}$ & -0.014 & 0.048 & $0.329^{*}$ & 0.001 & $0.246^{* *}$ \\
$\mathrm{~T}_{\text {upperarm }}$ & & & & 1.00 & 0.017 & 0.012 & $0.108^{* *}$ & 0.001 & $0.147^{* *}$ \\
$\mathrm{~T}_{\text {lowerarm }}$ & & & & & 1.00 & -0.001 & 0.000 & -0.006 & $0.51^{*}$ \\
$\mathrm{~T}_{\text {hand }}$ & & & & & & 1.00 & 0.032 & 0.010 & $0.871^{* *}$ \\
$\mathrm{~T}_{\text {thigh }}$ & & & & & & 1.00 & $0.134^{* *}$ & $0.319^{* *}$ \\
$\mathrm{~T}_{\text {calf }}$ & & & & & & & & 1.00 & $0.283^{* *}$ \\
$\mathrm{~T}_{\text {overall }}$ & & & & & & & & & 1.00 \\
\hline
\end{tabular}

(Note: $* * \mathrm{p}<0.01 ; * \mathrm{p}<0.05$, (two-tailed)

In summary, we identified the featured variables, and reduced the number of variables from 17 to 8 , i.e. sex, $\mathrm{AD}, \mathrm{BMI}, \mathrm{T}, \mathrm{RH}, \mathrm{V}, \mathrm{T}_{\text {chest }}$, and $\mathrm{T}_{\text {overall. }}$ These 8 variables are examined for sensitivity.

\subsubsection{SA of the feature variables}

Although the correlation analysis allows us to simplify the features in the C5.0 model, there is still a need to examine the degree to which these factors affect thermal sensation, and how to quantify their effects. To correctly interpret the results in the right perspective, we divided the 8 variables into three categories (i.e. environmental, individual, and physiological), and conducted a global SA to evaluate their effects. Figures 3-5 plot the main effects of the 8 features, respectively. The slopes of different inputs in Figures 3-5 give the information on whether the output of TSV is an increasing or decreasing function of the corresponding inputs; the solid lines are the mean values, and the dotted lines are the $95 \%$ intervals.

\section{(1) Individual features}

It was observed that the TSV showed linear change trends with the 8 variables increasing, as can be seen from Figures 3-5. Specifically, in Figure 3, the main effect differed in sex, with 1 being defaulted as female and 2 as male. In addition, with the increase of body $\mathrm{AD}$ and $\mathrm{BMI}$, the main effects caused by increasing $\mathrm{AD}$ and $\mathrm{BMI}$ decreased slightly, suggesting the effects of individual differences of $\mathrm{AD}$ and BMI on subjects' TSV changes were attenuated under such conditions. 


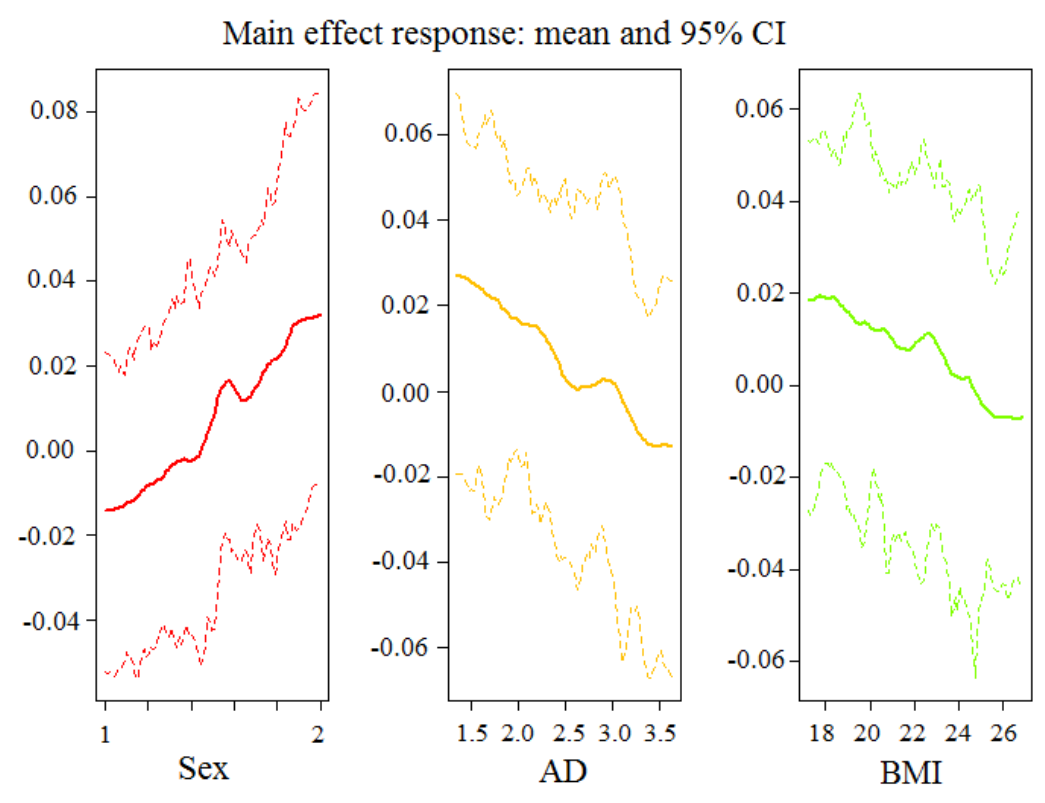

Figure 3 Sensitivity analysis (SA) results for three individual factors

The main effects of environmental parameters of T, RH, and V on TSV are plotted in Figure 4. From Figure 4, larger main effects of T and RH were observed on the TSV responses. Especially for $\mathrm{T}$, it revealed that with $\mathrm{T}$ increasing, the effect of increasing $1{ }^{\circ} \mathrm{C}$ on the TSV would be more significant. In addition, an in-depth observation on Figure 4 showed that the main effect responses tended to be stable when the T and RH were approximately $26{ }^{\circ} \mathrm{C} / 50 \% \mathrm{RH}$, and above $31{ }^{\circ} \mathrm{C} / 80 \% \mathrm{RH}$. This allows us to infer that when the $\mathrm{T}$ and $\mathrm{RH}$ are in a moderate zone, the thermal environment is neutral, such that the changes of $\mathrm{T}$ and $\mathrm{RH}$ have slight effects on subject thermal sensation. As the thermal sensation is limited to seven scale values with a maximum of +3 for hot, when the T and RH are high, subjects' TSV may stabilise at +3 , and can be higher for

449 Conversely, the $\mathrm{V}$ in Figure 4 displays an opposite trend of the main effect response,

450 i.e. increasing $\mathrm{V}$ has positive effects on a subject's thermal sensation, and produces a 451 decrease in TSV. Moreover, the values of the main effect responses for $\mathrm{V}$ were much 452 higher in Figure 4, indicating that the elevated V in a localised airflow system has a 453 significant cooling effect on subjects' TSV. 


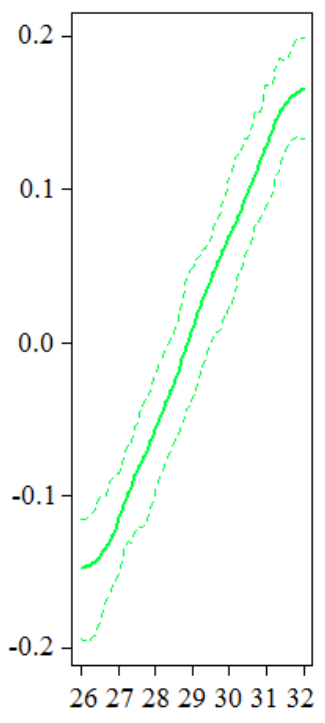

$\mathrm{T}$

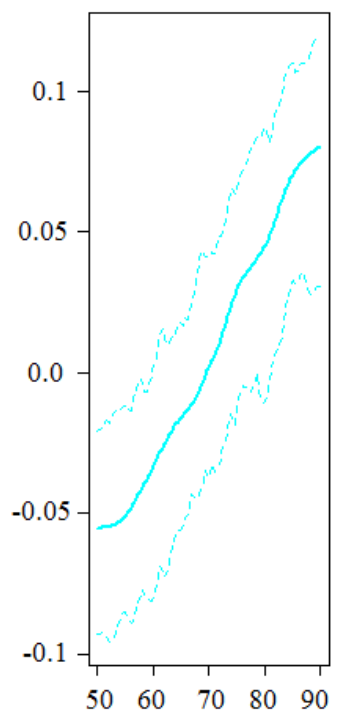

$\mathrm{RH}$

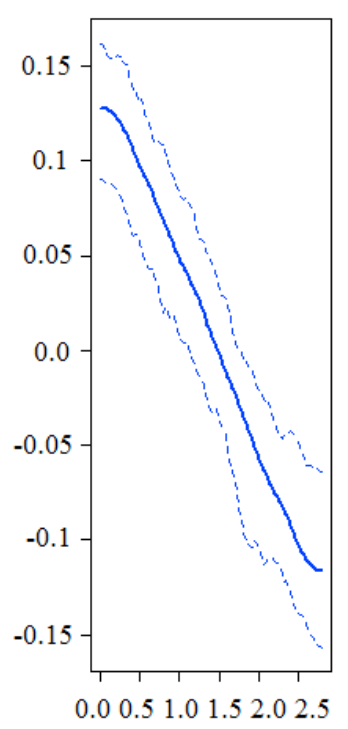

$\mathrm{V}$

Figure 4 SA results for physical factors

(3) Physiological features

As compared to the environmental factors shown in Figure 4, the main effects of $\mathrm{T}_{\text {overall }}$ and $\mathrm{T}_{\text {chest }}$ changes on the TSV responses in Figure 5 were slight in cases where skin temperatures were lower than approximately $32{ }^{\circ} \mathrm{C}$. However, the main effects 460 increased remarkably when the skin temperatures increased above $32{ }^{\circ} \mathrm{C}$. Considering 461 the comfort limits for skin temperatures, this indicates that when the skin temperatures 462 of subjects are lower than the thresholds (e.g. $32{ }^{\circ} \mathrm{C}$ in this study), the TSV is in a comfortable range, and is slightly affected by skin temperatures. When the skin temperatures increase beyond the comfort zones, the TSV of subjects tends to increase significantly.

Main effect response: mean and $95 \% \mathrm{CI}$
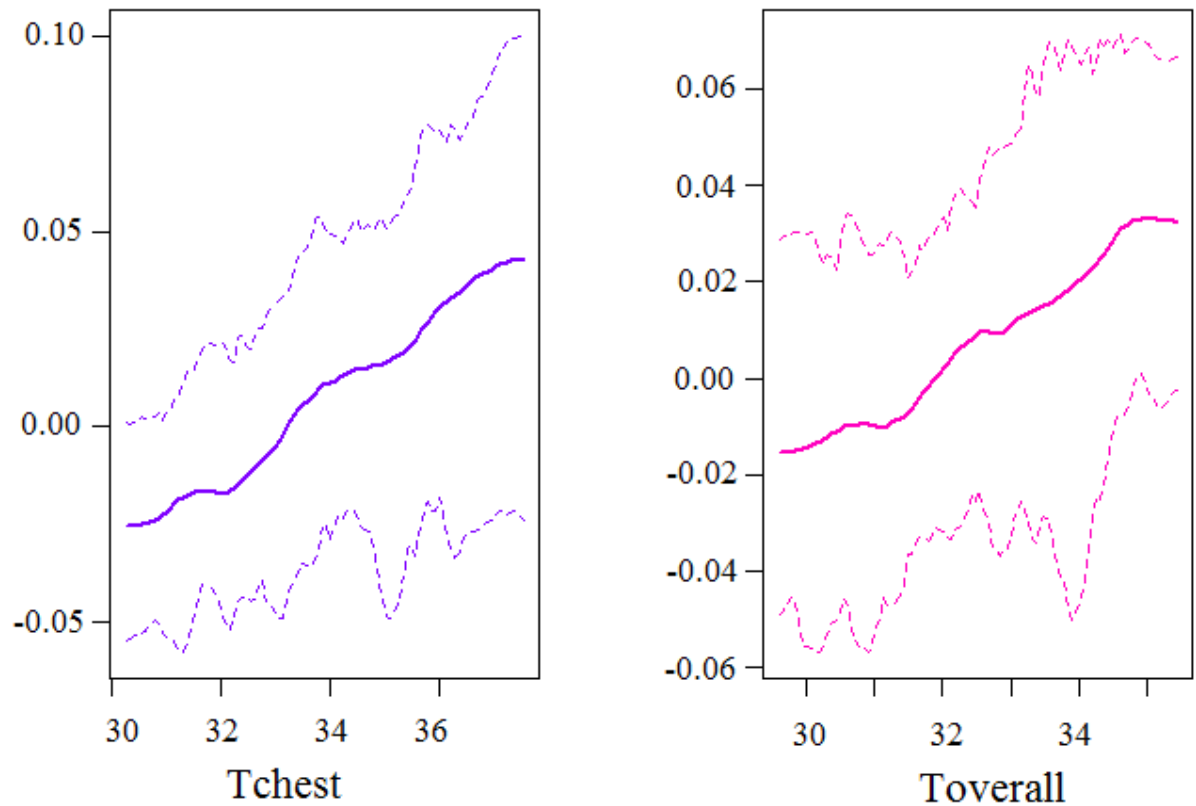


\section{(4) Global effects}

To display the main effects for all parameters using a single plot, Figure 6 further summarises the first-order sensitivity and the total effect sensitivity of the 8 indices. In Figure 6, the first-order sensitivity indices quantify the changes of output variables respectively caused by individual input variables, and the total effect sensitivity indices reflect the interactive effects of all of the input variables on the output variable. From Figure 6, it is clearly observed that $\mathrm{T}$ is a major contributor, leading to the most sensitive TSV responses with increasing $\mathrm{T}$. The $\mathrm{V}$ and $\mathrm{RH}$ are ranked as the second and third contributors to the TSV changes, respectively. This is to some degree different from the individual effects depicted in Figure 5, which may be explained by the coupled effects of $\mathrm{T}, \mathrm{RH}$, and $\mathrm{V}$. By contrast, the individual and physiological features are roughly the same, sharing the small values of sensitivity responses to TSV. However, for the total sensitivity, a remarkable change is found in Figure 6. Although the overall distribution trend of the 8 variables remains, the total effects increase when considering the interactions among 8 variables, especially for T. That the sensitivity indices do not sum to one indicates that the interactive effects between two or more variables are important for individual thermal sensation evaluation under local airflow conditions. Overall, Figure 6 gives a visual impression of the effects of the selected 8 feature variables on the variation of TSV, and quantifies their individual and coupled effects, which are believed to be beneficial for the evaluation and design of localised airflow systems in buildings.
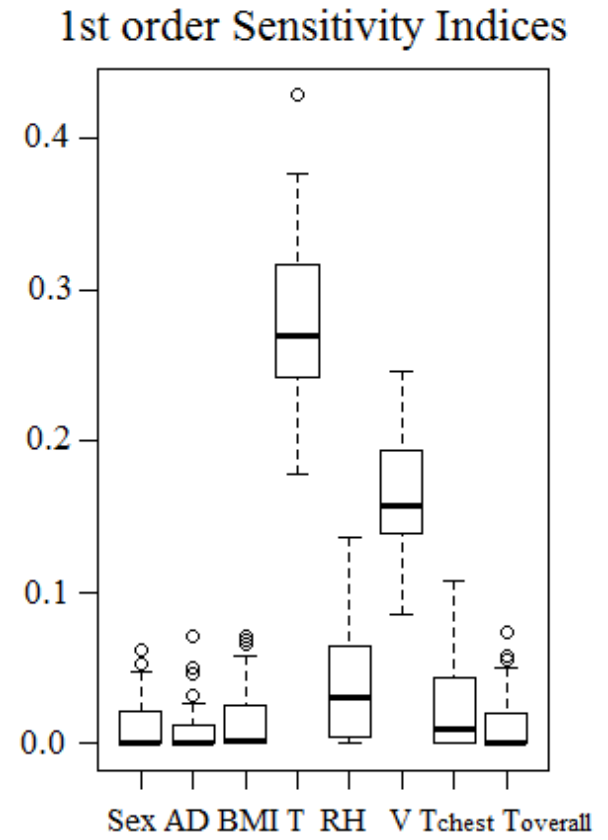

\section{Total effect Sensitivity Indices}

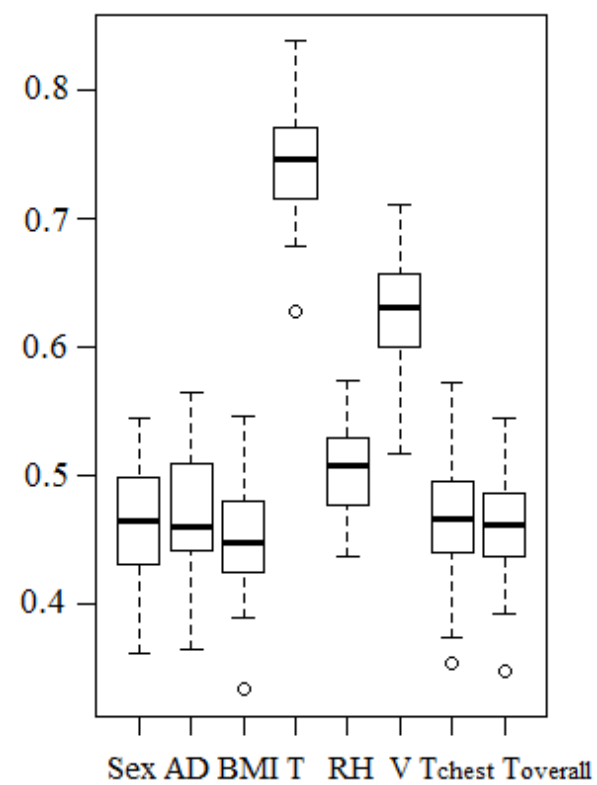

Input Variables

Figure 6 Full SA results for all feature variables 


\subsection{Model verification}

Here, further discussion is provided as to whether and to what degree the reduction of input variables might compromise the prediction performance of the obtained C5.0 model, as compared to the iteration using e.g. 17 variables. A new database with 8 feature variables and 1 output variable is created via inputs filtering, as shown in Figure 2 in solid red lines. Using the same settings as in Section 3.1, the data are also divided into training and testing sets, and the predictive performance of the obtained C 5.0 model is examined and verified. The result shows that the new C5.0 model using 8 inputs has a high predictive performance of $82.30 \%$, even though it is slightly lower than the aforementioned performance of $83.99 \%$ using 17 variables as shown in Table 4. This indicates that the C5.0 model is better for predicting human thermal comfort in a local airflow system with as few as 8 variables, which is expected to simplify the C5.0 model to facilitate its use in applications.

One additional advantage of choosing the C5.0 model is that it can generate a interpretable model to understand how the model implements rules and can run faster with a large database, as compared with some complex models such as Random forest and SVM[26]. Therefore, we demonstrate the decision rules in the C5.0 model and simplify the process using the first four layers as example, as shown in Figure 7. Consistent with the sensitivity analysis, the model in Figure 7 adopts the environmental parameters as the prior feature nodes, to divide different categories and layers. With or without a local air velocity, the C5.0 model first takes V as the root node of the tree, as seen in Figure 7. In particular, the C5.0 model only follows a rule of binary classification for features, from the root node to leaf node. Therefore, the original division splits $\mathrm{V}$ into two categories of $\leqslant 0 \mathrm{~m} / \mathrm{s}$ and $>0 \mathrm{~m} / \mathrm{s}$. However, it is unreasonable in reality for $\mathrm{V}$ to be under $0 \mathrm{~m} / \mathrm{s}$. Therefore, we fine-tune the classification tree in Figure 7 with $\mathrm{V}=0 \mathrm{~m} / \mathrm{s}$. Starting from root node, the data are split into two categories, using a $\mathrm{T}$ baseline of $28{ }^{\circ} \mathrm{C}$ in the second layer. The third layer introduces $\mathrm{RH}$ as the feature, and divides according to the baselines of $75 \%$ and $55 \%$ for $\mathrm{T} \leqslant 28{ }^{\circ} \mathrm{C}$ and $\mathrm{T}>28{ }^{\circ} \mathrm{C}$, respectively. The fourth layer further adopts $\mathrm{RH}$ and BMI as leaf nodes. By contrast, the classification rule is slightly different from that when $\mathrm{V}$ is above $0 \mathrm{~m} / \mathrm{s}$. That is, with $\mathrm{V}>0 \mathrm{~m} / \mathrm{s}$, the $\mathrm{T}$ and $\mathrm{RH}$ are adopted as feature variables in the third layer for classification. When $\mathrm{T}$ is equal to or under $28^{\circ} \mathrm{C}$, T is introduced for the third layer $\left(\mathrm{T} \leqslant 26^{\circ} \mathrm{C}\right.$ (neutral) and $\mathrm{T}>26^{\circ} \mathrm{C}$ (warm)). When $\mathrm{T}$ is above $28^{\circ} \mathrm{C}$, the $\mathrm{RH}$ is adopted in the third layer, with $\mathrm{RH} \leqslant 75 \%$ and $\mathrm{RH}>75 \%$. This suggests that the effect of RH on human thermal comfort is coupled with $\mathrm{T}$, and plays a dominant role under higher $\mathrm{T}$ values and humidity. 


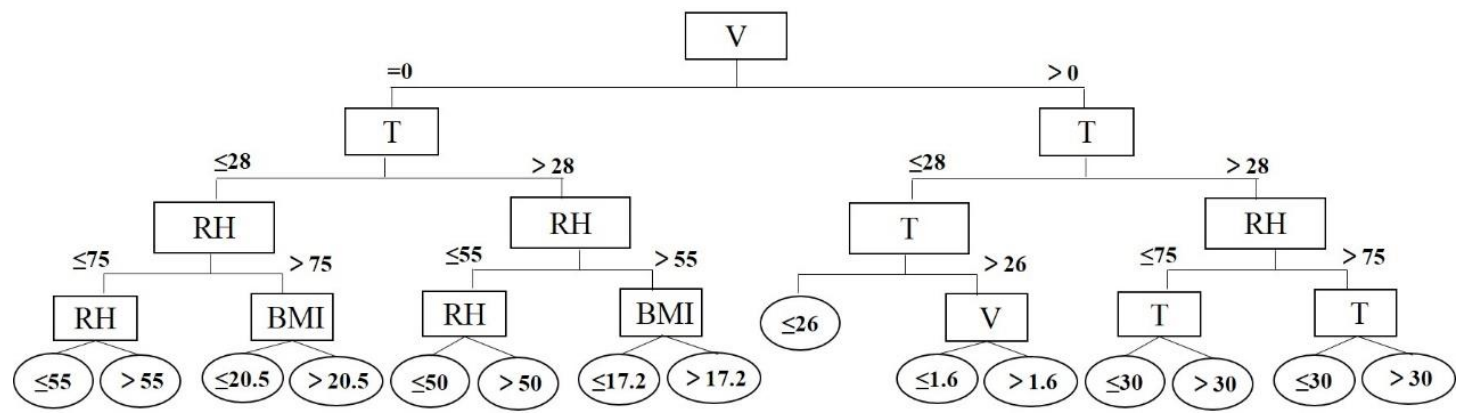

Figure 7 Classification Tree C5.0 model for localised airflow evaluation

\section{Discussion and limitations}

The above analysis (depicted in Figure 7) identifies the most significant features affecting TSV at each layer of the tree with different discriminative approaches, and is superior to some other models. Kim[26] compared the performance of six typical machine learning algorithms used to develop personal comfort models; he argued that although algorithms with capabilities to control high dimensions and noise in the data (e.g. Random forest, regularised logistic regression, kernel SVM (kSVM)) could produce higher accuracy, they were more computationally expensive. In light of this, the C5.0 model in the current study significantly reduces the numbers of feature variables; meanwhile, it still predicts the individual thermal sensations well (higher than 80\%). Most important, the machine learning models are superior at continuously and automatically improving themselves through repeated learning and training [26]. It is thus believed that by performing an incremental restoration of data, the prediction performance of the C5.0 model for predicting personal thermal comfort with 8 input variables could be improved, i.e. more in-depth. In this way, this work can be referred to for comfort evaluation for a localised airflow system and guide application of such a system, in parallel with reduced dependence on HVAC systems and more energy-saving potential.

However, although this study identifies the significant influencing variables in localised airflow systems and builds an appropriate classification tree model based on C5.0, some limitations should be discussed for the current study, to make better interpretation of the results and inspire further studies. The results in this study are based on a database including three local air supply forms, where subjects were exposed to airflow for $20 \mathrm{~min}$, and recovered for 15-20 min between two different $\mathrm{V}$ levels. As under warm/hot conditions, the inner body heat storage of subjects would increase over the periods without airflow, the study may exaggerate the subjects' real thermal sensation on the cooling effect of air velocity, when the airflow is subsequently given. This would have effects on the obtained database. However, some experiments

558 designed without recovery periods, or with a short recovery time [60-63], could cause

559 the inclusion of subjects' thermal memories from a previous thermal experience, 560 potentially resulting in deviations for the subjective evaluations. Therefore, balancing 
the variant factors in a localised airflow system and the contradictions between time, cost, and experimental designs for different purposes should be considered for future studies.

The preferred air velocity of occupants is believed to have a "time and fatigue" effect, as the demand for air velocity for people would differ from short-term exposure to long-term exposure[64, 65]. The lab experiments used in this study were designed to explore the cooling effect of air movement for a localised airflow system and the exposure durations were limited, with the time-dependent variations of subject thermal sensations being thus exclusively considered. The term "alliesthesia" has been paid increasing attention in the dynamic thermal comfort field, and describes a sensation of pleasantness that occurs only with dynamic thermal stimuli on a human skin surface[66, 67]. As for long-term exposure to airflow in real building environments, the annoyance caused by a constant air velocity may increase over time[64]. An air velocity over $1 \mathrm{~m} / \mathrm{s}$ may exert extra pressure on the human body surface[68] and cause eye irritation [69]; moreover, the high air velocity may cause thermal draught for occupants in hot environments $[15,65]$. In that case, a new database including a time variable should be built, to retrain the current C5.0 model for long-term comfort evaluation.

In addition, to achieve such 'temporal alliesthesia' for people, the local air supply system should be regulatory for occupants. According to some studies exploring the personal control of localised air supply systems[23, 70], the expected air velocity decreases and the acceptable temperature limits increase when providing personal control to occupants. However, considering that occupants' demands and regulations on air velocity as integrated with a time factor remain incompletely understood, subjects in these three series of experiments were restricted from regulating the local airflow system. Therefore, some deviations may exist when the C5.0 model is applied to a personally-controlled system. As the occupant behaviours play dominant roles for thermal comfort and energy consumption in buildings, in-depth research should be conducted for the effects of personal control on localised air supply systems and the corresponding demands.

From a practical perspective, the challenges ahead model application would depend upon some factors[71]: (1) the quality and importance of the monitored parameters; (2) the availability of devices to monitor these parameters; and (3) the

593 operation and cost for long term measurements. The current study identifies 8 features 594 for C5.0 model prediction, but some individual parameters and physiological indices 595 may be difficult for data monitoring and collection in buildings. Future studies for 596 application of the localised airflow system in buildings should select more accessible 597 variables, or alternative indices, without compromising the prediction performance of 598 the C5.0 model.

\section{5. Conclusions}

600 This work, based on three series of experiments with localised airflow systems, i.e. 601 IASN, NIASN, and FF, identifies the appropriate machine learning model - the 

with 17 original variables.

The sensitivity analysis quantifies the main effects of 8 major variables in a localised airflow system. $\mathrm{T}$ is the major contributor leading to the most sensitive response of TSV, followed by $\mathrm{V}$ and $\mathrm{RH}$. The total effects increase using global sensitivity analysis, indicating significant interactive effects.

The C5.0 model is then modified with the 8 sensitive features, and displays a better prediction performance $(82.3 \%)$. A tree model is obtained to demonstrate the decision rules in the C5.0 model. The model employs $\mathrm{V}(=0 \mathrm{~m} / \mathrm{s},>0 \mathrm{~m} / \mathrm{s})$ as the first feature variable and root node, and $\mathrm{T}\left(\leqslant 28^{\circ} \mathrm{C},>28^{\circ} \mathrm{C}\right)$ as the second feature variable and leaf node. This is highly interpretable, and responds to the sensitivity analysis. With the lowered cost of sensors and ubiquitous wireless connectivity, it is believed that the C5.0 model will be further improved, thanks to its continuous learning and ability to automatically train itself.

\section{Acknowledgements}

This work was supported by the National Key R\&D Program of China (Grant No: 2016YFC0700301) supported by the Ministry of Science and Technology of China. The authors would also thank for all the participants in these experiments.

\section{References}

[1] M. B. Givoni, Climate and Architecture (Second ed), Van Nostrand Reinhold Company, New York, 1976.

624 [2] K.L. D. Watson, Climatic Design, McGraw-Hill Book Company, New York, 1983.

[3] R.F. Rupp, N.G. Vásquez, R. Lamberts, A review of human thermal comfort in the built environment,

[4] M. Veselý, W. Zeiler, Personalized conditioning and its impact on thermal comfort and energy performance-A review, Renew Sust Energ Rev. 34(3)(2014)401-408.

[5] A.K. Mishra, M.G.L.C. Loomans, J.L.M. Hensen, Thermal comfort of heterogeneous and dynamic indoor conditions-An overview, Build Environ. 109(2016)82-100.

631 [6] H. Zhang, F. Bauman, E. Arens, Y.C. Zhai, Reducing Building Over-cooling by Adjusting HVAC

632 Supply Airflow Setpoints and Providing Personal Comfort Systems, In: Indoor Air 2018 conference 633 proceedings, Philadelphia, PA, USA, 2018.

634 [7] H. Zhang, E. Arens, Y. Zhai, A review of the corrective power of personal comfort systems in non635 neutral ambient environments, Build Environ. 91(2015)15-41.

636 [8] S.C. Sekhar, N. Gong, K.W. Tham, K.W. Cheong, A.K. Melikov, D.P. Wyon, P.O. Fanger, Findings 637 of Personalized Ventilation Studies in a Hot and Humid Climate, HVAC \& R Res. 11(4)(2005)603-620.

638 [9] Y. He, N. Li, J. Peng, W. Zhang, Y. Li, Field study on adaptive comfort in air conditioned dormitories 639 of university with hot-humid climate in summer, Energ Build. 119(2016)1-12.

640 [10] J. Langevin, P.L. Gurian, J. Wen, Tracking the human-building interaction: A longitudinal field 641 study of occupant behaviour in air-conditioned offices, J Environ Psychol. 42(2015)94-115. 

adaptive behaviour in Japanese university buildings with free running and cooling mode offices during summer, Build Environ. 105(2016)332-342.

[12] M. Indraganti, R. Ooka, H.B. Rijal, Thermal comfort in offices in summer: Findings from a field study under the "setsuden" conditions in Tokyo, Japan, Build Environ. 61(61)(2013)114-132. for improving health, comfort, and performance at high room temperature and humidity, Indoor Air. 23(3)(2013)250-263.

[14] Y. Zhai, C. Elsworth, E. Arens, H. Zhang, Y. Zhang, L. Zhao, Using air movement for comfort during moderate exercise, Build Environ. 94(1)(2015)344-352.

[15] L. Huang, Q. Ouyang, Y. Zhu, L. Jiang, A study about the demand for air movement in warm environment, Build Environ. 61(61)(2013)27-33.

[16] W. Sun, K.W. Tham, W. Zhou, N. Gong, Thermal performance of a personalized ventilation air terminal device at two different turbulence intensities, Build Environ. 42(12)(2007)3974-3983. [17] N. Gong, K.W. Tham, A.K. Melikov, D.P. Wyon, S.C. Sekhar, K.W. Cheong, The Acceptable Air Velocity Range for Local Air Movement in The Tropics, HVAC \& R Res. 12(4)(2006)1065-1076. [18] J. Toftum, A. Melikov, A. Tynel, M. Bruzda, P. Olefanger, Human Response to Air Movement an Evaluation of ASHRAE' s Draft Criteria (RP-843), HVAC \& R Res. 9(2)(2003)187-202.

660 [19] A.K. Melikov, R. Cermak, M. Majer, Personalized ventilation: evaluation of different air terminal 661 devices, Energ Build. 34(8)(2002)829-836.

662 [20] A. Melikov, B. KovÃ, J. Kaczmarczyk, M. Duszyk, T. Sakoi, Human response to local convective and radiant cooling in a warm environment, HVAC \& R Res. 19(8)(2013)1023-1032.

664 [21] M. Chludzińska, A. Bogdan, The role of the front pattern shape in modelling personalized airflow and its capacity to affect human thermal comfort, Build Environ. 126(2017)373-381.

666 [22] H. Pallubinsky, L. Schellen, T.A. Rieswijk, C.M.G.A. Breukel, B.R.M. Kingma, W.D.V.M. Lichtenbelt, Local cooling in a warm environment, Energ Build. 113(2016)15-22.

668 [23] Y. He, N. Li, N. Li, J. Li, J. Yan, C. Tan, Control behaviours and thermal comfort in a shared room with desk fans and adjustable thermostat, Build Environ. 136(2018)213-226.

670 [24] Y. Zhai, H. Zhang, Y. Zhang, W. Pasut, E. Arens, Q. Meng, Comfort under personally controlled air movement in warm and humid environments, Build Environ. 65(88)(2013)109-117.

672 [25] K.P. Murphy, Machine learning: a probabilistic perspective (adaptive computation and machine learning series, In: The MIT Press, Cambridge, Massachusetts, London, England, 2012.

674 [26] J. Kim, Y. Zhou, S. Schiavon, P. Raftery, G. Brager, Personal comfort models: Predicting individuals' thermal preference using occupant heating and cooling behaviour and machine learning, Build Environ. 129(2018)96-106.

677 [27] L. Jiang, R. Yao, Modelling personal thermal sensations using C-Support Vector Classification (C678 SVC) algorithm, Build Environ. 99(2016)98-106.

679 [28] J. Kim, S. Schiavon, G. Brager, Personal comfort models-A new paradigm in thermal comfort for 680 occupant-centric environmental control, Build Environ. 132(2018)114-124.

681 [29] D. Zhai, Y.C. Soh, Balancing Indoor Thermal Comfort and Energy Consumption of ACMV Systems 682 via Sparse Swarm Algorithms in Optimizations, Energ Build. 149(2017)1-15.

683 [30] A.K. Melikov, Personalized ventilation, Indoor Air. 14(S7)(2004)157-167. 
[31] M. Chludzińska, A. Bogdan, The effect of temperature and direction of airflow from the personalised ventilation on occupants' thermal sensations in office areas, Build Environ. 85(2015)277-286.

[32] F. Faul, E. Erdfelder, A.G. Lang, A. Buchner, G*Power 3: a flexible statistical power analysis program for the social, behavioral, and biomedical sciences, Behav Res Methods. 39(2)(2007)175-191. [33] ASHRAE 55: 2013, Thermal Environmental Conditions for Human Occupancy, In: American Society of Heating, Refrigerating and Air-Conditioning Engineers, Atlanta, GA, 2013.

[34] H. Zhang. Human Thermal Sensation and Comfort in Transient and Non-Uniform Thermal Environments. Berkeley: University of California, 2003. [35] E. Arens, H. Zhang, C. Huizenga, Partial- and whole-body thermal sensation and comfort-Part II: Non-uniform environmental conditions, J Therm Biol. 31(1-2)(2006)60-66. [36] E. Arens, H. Zhang, Thermal sensation and comfort models for non-uniform and transient environments, part III: whole-body sensation and comfort, Build Environ. 45(2)(2010)399-410. [37] EN ISO 7726, Ergonomics of the thermal Environment. Instruments for Measuring Physical Quantities. European Committee for Standardization, 2001.

698 [38] EN 15251, Indoor Environmental Input Parameters for Design and Assessment of Energy 699 Performance of Buildings Addressing Indoor Air Quality, Thermal Environment, Lighting and Acoustics. 700 European Committee for Standardization, Brussel, Belgium, 2007.

701 [39] D. du Bois, A formula to estimate approximate surface area if height and weight are known, Arch 702 Internal Medicine. 17(1916)863-871.

703 [40] N. Charkoudian, Human thermoregulation from the autonomic perspective, Auton Neurosci Basic 704 Clin. 196(2016)1-2.

705 [41] A.P. Gagge, Y. Nishi, Heat Exchange Between Human Skin Surface and Thermal Environment706 Handbook of Physiology. American Physiological Society, Bethesda, 1977.

707 [42] M. Nakamura, T. Yoda, L.I. Crawshaw, S. Yasuhara, Y. Saito, M. Kasuga, K. Nagashima, K. 708 Kanosue, Regional differences in temperature sensation and thermal comfort in humans, J Appl Physiol. 709 105(6)(2008)1897-1906.

710 [43] H. Zhang, C. Huizenga, E. Arens, D. Wang, Thermal sensation and comfort in transient non-uniform 711 thermal environments, Eur J Appl Physiol. 92(6)(2004)728-733.

712 [44] World Medical Association(WMA). WMA Declaration of Helsinki - Ethical Principles for Medical 713 Research Involving Human Subjects, in 64th WMA General Assembly, Fortaleza, Brazil, October 2013.

714 [45] A. Ghahramani, C. Tang, B. Becerik-Gerber, An online learning approach for quantifying 715 personalized thermal comfort via adaptive stochastic modeling, Build Environ. 92(2015)86-96.

716 [46] M. Vellei, M. Herrera, D.F.D. Pando, S. Natarajan, The influence of relative humidity on adaptive 717 thermal comfort, Build Environ. 124(2017)171-185.

718 [47] T. Chaudhuri, D. Zhai, Y.C. Soh, H. Li, L. Xie, Random Forest based Thermal Comfort Prediction 719 from Gender-specific Physiological Parameters using Wearable Sensing Technology, Energ Build. 720 166(2018)31-406.

721 [48] A. Ghahramani, C. Tang, Z. Yang, B. Becerik-Gerber, A Study of Time-Dependent Variations in 722 Personal Thermal Comfort via a Dynamic Bayesian Network. In: First International Symposium on 723 Sustainable Human-Building Ecosystems Conference proceedings, (2015)99-107.

724 [49] T.C.T. Cheung, S. Schiavon, E.T. Gall, M. Jin, W.W. Nazaroff, Longitudinal assessment of thermal 725 and perceived air quality acceptability in relation to temperature, humidity, and $\mathrm{CO} 2$ exposure in 
Singapore, Build Environ. 115(2017)80-90.

727 [50] C. Dai, H. Zhang, E. Arens, Z. Lian, Machine learning approaches to predict thermal demands using skin temperatures: Steady-state conditions, Build Environ. 114(2017)1-10.

729 [51] W. Liu, Z. Lian, B. Zhao, A neural network evaluation model for individual thermal comfort, Energ 730 Build. 39(10)(2007)1115-1122.

731 [52] https://www.ibm.com/products/spss-modeler.

732 [53] T.J. Santner, B.J. Willianms, The Design and Analysis of Computer Experiments (Springer Series 733 in Statistics). Springer-Verlag, Berlin, Germany, 2003.

734 [54] A. Saltelli, K. Chan, E.M. Scott, Sensitivity Analysis, John Wiley and Sons, 2008.

735 [55] R. Gagnon, L. Gosselin, S. Decker, Sensitivity analysis of energy performance and thermal comfort 736 throughout building design process, Energ Build. 164(2018)278-294.

737 [56] W. Tian, A review of sensitivity analysis methods in building energy analysis, Renew Sust Ener 738 Rev. 20(4)(2013)411-419.

739 [57] M.A.T. Robert, B. Gramacy, Categorical inputs, sensitivity analysis, optimization and importance 740 tempering with tgp version 2, an R package for treed Gaussian process models. J Stat Soft. 33(06)(2016).

741 [58] A. Bogdan, M. Chludzinska, Assessment of Thermal Comfort Using Personalized Ventilation, 742 HVAC \& R Res. 16(4)(2010)529-542.

743 [59] Z. Fang, H. Liu, B. Li, X. Du, A. Baldwin, Investigation of the effects of temperature for supplied 744 air from a personal nozzle system on thermal comfort of air travelers, Build Environ. 126(2017)82-97.

745 [60] M.A. Skwarczynski, A.K. Melikov, J. Kaczmarczyk, V. Lyubenova, Impact of individually 746 controlled facially applied air movement on perceived air quality at high humidity, Build Environ. 747 45(10)(2010)2170-2176.

748 [61] A.K. Melikov, M.A. Skwarczynski, J. Kaczmarczyk, J. Zabecky, Use of personalized ventilation 749 for improving health, comfort, and performance at high room temperature and humidity, Indoor Air. $750 \quad 23(3)(2013) 250-263$.

751 [62] L. Huang, Q. Ouyang, Y. Zhu, L. Jiang, A study about the demand for air movement in warm 752 environment, Build Environ. 61(61)(2013)27-33.

753 [63] Y. Zhai, Y. Zhang, H. Zhang, W. Pasut, E. Arens, Q. Meng, Human comfort and perceived air 754 quality in warm and humid environments with ceiling fans, Build Environ. 90(2015)178-185.

755 [64] Y. Wang, Z. Lian, P. Broede, L. Lan, A time-dependent model evaluating draft in indoor 756 environment, Energ Build. 49(2)(2012)466-470.

757 [65] C. Du, B. Li, H. Liu, Y. Wei, M. Tan, Quantifying the cooling efficiency of air velocity by heat loss 758 from skin surface in warm and hot environments, Build Environ. 136(2018)146-155.

759 [66] M. Cabanac, Physiological role of pleasure, Science. 173(4002)(1971)1103-07.

760 [67] R. de Dear, Revisiting an old hypothesis of human thermal perception: Alliesthesia, Build Res 761 Inform. 39(2)(2011)108-117.

762 [68] J. Toftum, G. Langkilde, P.O. Fanger, New indoor environment chambers and field experiment 763 offices for research on human comfort, health and productivity at moderate energy expenditure, Energ 764 Build. 36(9)(2004)899-903.

765 [69] P. Wolkoff, Ocular discomfort by environmental and personal risk factors altering the precorneal 766 tear film, Toxicol Lett. 199(3)(2010)203-212.

767 [70] M. Luo, B. Cao, W. Ji, Q. Ouyang, B. Lin, Y. Zhu, The underlying linkage between personal control 
768 and thermal comfort: Psychological or physical effects? Energ Build. 111(2016)56-63.

769 [71] P. Kumar, C. Martani, L. Morawska, L. Norford, R. Choudhary, M. Bell, M. Leach, Indoor air 770 quality and energy management through real-time sensing in commercial buildings, Energ Build. 771 111(2016)145-153.

772

773 